Article

\title{
Copper Adsorption by Magnetized Pine-Needle Biochar
}

\author{
Eleni Nicolaou, Katerina Philippou*, Ioannis Anastopoulos $\mathbb{D}$ and Ioannis Pashalidis \\ Department of Chemistry, University of Cyprus, P.O. Box 20537, 1678 Nicosia, Cyprus; \\ eleninicol@hotmail.com (E.N.); anastopoulos_ioannis@windowslive.com (I.A.); pspasch@ucy.ac.cy (I.P.) \\ * Correspondence: kphili03@ucy.ac.cy
}

Received: 17 September 2019; Accepted: 26 November 2019; Published: 2 December 2019

\begin{abstract}
The $\mathrm{Cu}(\mathrm{II})$ adsorption from aqueous solutions by magnetic biochar obtained from pine needles has been studied by means of batch-type experiments. The biochar fibers have been magnetized prior (pncm: carbonized-magnetized pine needles) and after oxidation (pncom: carbonized-oxidized-magnetized pine needles) and have been used as adsorbents to study the presence of carboxylic moieties on the magnetization and following adsorption process. The effect of $\mathrm{pH}(2-10)$, initial metal concentration $\left(10^{-5}-9 \cdot 10^{-3} \mathrm{~mol} \cdot \mathrm{L}^{-1}\right)$ and contact time $(0-60 \mathrm{~min})$ has been studied by varying the respective parameter, and the adsorbents have been characterized by Fourier transform infrared (FTIR) and X-ray diffraction (XRD) measurements prior and after $\mathrm{Cu}$ (II)-adsorption. FTIR measurements were performed to investigate the formation of surface species and XRD measurements to record possible solid phase formation and characterize formed solids, including the evaluation of their average crystal size. The data obtained from the batch-type studies show that the oxidized magnetic biochar (pncom) presents significantly higher adsorption capacity $\left(1.0 \mathrm{mmol} \mathrm{g}^{-1}\right)$ compared to pncm $\left(0.4 \mathrm{mmol} \mathrm{g}^{-1}\right)$, which is ascribed to the synergistic effect of the carboxylic moieties present on the pncom surface, and the adsorption process follows the pseudo-second order kinetics. On the other hand, the FTIR spectra prove the formation of inner-sphere complexes and XRD diffractograms indicate $\mathrm{Cu}(\mathrm{II})$ solid phase formation at $\mathrm{pH} 6$ and increased metal ion concentrations.
\end{abstract}

Keywords: copper adsorption; magnetized pine needle biochar; isotherms; kinetics; FTIR and XRD studies

\section{Introduction}

The presence of toxic metal ions in wastewaters is a major environmental issue due to their toxicity, which may harm the environment and affect human health. Therefore, the treatment of contaminated wastewaters before disposal into environmental compartments such as soils and natural water systems is a vital necessity. There are many techniques used for the decontamination of the wastewater from toxic metals/metalloids, such as precipitation and flocculation using chemical reagents, flotation techniques, ion exchange procedures, and membrane filtration processes [1].

Adsorption-based remediation technologies are of particular interest because of the existing know-how and their relatively simple and effective application in waste water treatment. Recently, there have been several studies related to abundant and low cost biomass by-products [2], including biochars [3]. Activated carbon and biochar materials are used in many technological applications and analytical processes because of their high affinity for metal/metalloid ions and organic pollutants, which is associated with their large surface area and the presence of active surface groups, particularly after appropriate chemical modification [4-9]. 
The application of activated carbons (AC) to treat large volumes of wastewater produced by domestic water use and industry is restricted due to its relatively high production costs. More specifically, the biochar and AC cost is $\$ 350-\$ 1200$ and $\$ 1100-\$ 1700$ per tonne, respectively [10]. Moreover, AC materials are produced from non-renewable coal and are thermally activated to improve/promote their adsorption characteristics [10]. On the other hand, biochar materials can be produced from biomass by-products and are also applied as soil amendments to enhance soil carbon sequestration and improve soil productivity [11]. In wastewater treatment applications, biochars are usually chemically modified to increase their adsorption capability and selectivity towards specific pollutants [12]. These techniques include physical activation (steam, gas), chemical activation (alkali and acid treatments) and impregnation methods or combined methods [12].

Hence, modified biochar materials are very attractive adsorbents because they could effectively be used for the removal and recovery of precious and industrial metals from process solutions and wastewaters, and they could replace activated carbons widely used in the treatment and purification of waters. Generally, all types of biomass could be converted into biochar. However, lignocellulosic biomasses are much better precursors because of their higher density and hardness. In addition, the adsorption capacity and selectivity of the biochars towards cations can be significantly increased after chemical oxidation of their surface, which results in the formation of oxygen-containing moieties (e.g., hydroxyl and carbonyl groups) [4,13,14]. Moreover, deposition of metal oxides (e.g., $\mathrm{MnO}_{2}$ and $\mathrm{Fe}_{3} \mathrm{O}_{4}$ ) on the biochar surface may further enhance the adsorption capacity and selectivity of the material towards certain metal ions. Moreover, magnetization of the material allows easy separation of the adsorbed contaminants using an external magnetic field [6,7,15].

This study aims at investigating the adsorption and removal of $\mathrm{Cu}(\mathrm{II})$ from water solutions using magnetized biochar adsorbents. Aliquots of the biochar carbonized pine needles (pnc), which has been obtained from pine needles, were chemically oxidized (pnco) and both materials pnc and pnco were magnetized resulting in pncm (carbonized-magnetized pine needles) and pncom (carbonized-oxidized-magnetized pine needles), respectively. $\mathrm{Cu}$ (II) has been used as adsorbate as it can be easily measured using the $\mathrm{Cu}(\mathrm{II})$ ion selective electrode, has low toxicity for humans, and could be a good analogue for $\mathrm{Cd}(\mathrm{II})$ and $\mathrm{Pb}$ (II). The fibrous structure of the pine needles, which is an abundant and otherwise useless biomass, is expected to remain in the derived biochar resulting in a robust, high surface biochar, which is further modified by precipitating iron-oxides on its surface and forming a magnetic biochar composite, with desired properties such as magnetism and enormous external surface due to the presence of iron-oxide nanoparticles. The study is based on the investigation of physicochemical parameters such as $\mathrm{pH}$, copper concentration and contact time, which affect the $\mathrm{Cu}$ (II) removal by means of batch-type experiments. Moreover, Fourier transform infrared (FTIR) and X-ray diffraction (XRD) measurements are performed to understand the adsorption mechanism, which is of fundamental importance for the development of water treatment processes regarding the removal and recovery of precious and toxic metals/metalloids.

\section{Experimental}

\subsection{Materials}

The experiments were carried out under ambient conditions. The $\mathrm{Cu}(\mathrm{II})$ stock solutions were prepared by dissolution of $\mathrm{CuSO}_{4} \cdot 5 \mathrm{H}_{2} \mathrm{O}$ (Merck, $>98 \%$, Darmstadt, Germany). The needles were obtained from a domestic pine tree (Pinus brutia Pegeia, Cyprus) and after cleaning and washing, the needles were carbonized and oxidized as previously described [8] to produce the carbonized pine needles (pnc) and following the chemically oxidized pine needle (pnco) biochar. Iron(II) sulfate heptahydrate, $\mathrm{FeSO}_{4} \cdot 7 \mathrm{H}_{2} \mathrm{O}$ (Sigma-Aldrich, $99 \%$, St. Louis, MO, USA) and anhydrous iron(III) chloride, $\mathrm{FeCl}_{3}$ (Merck, 98\%, Darmstadt, Germany) were used as received. The corresponding magnetic biochars (pncm and pncom) were produced according to Oliveira et al. [16]. Specifically, certain amounts of $\mathrm{FeSO}_{4} \cdot 7 \mathrm{H}_{2} \mathrm{O}(3.89 \mathrm{~g})$ and $\mathrm{FeCl}_{3}(4.54 \mathrm{~g})$ were mixed together with biochars $(9.72 \mathrm{~g}$ ) (weight ratio 3:1) 
and deionized water $(400 \mathrm{~mL})$, at $70{ }^{\circ} \mathrm{C}$, under constant stirring. Then, $100 \mathrm{~mL}$ of $5 \mathrm{M} \mathrm{NaOH}$ (Merck, Darmstadt, Germany) was dropwise added to the mixture in order to precipitate the iron oxides on the biochar surface. Finally, the products were filtered using a glass frit funnel and washed with distilled water until nearly neutral $\mathrm{pH}$ and dried overnight in a vacuum-oven at $110^{\circ} \mathrm{C}$. The materials were characterized by Fourier transform infrared spectroscopy (FTIR, spectrometer 8900, Shimadzu Europa GmbH, Duisburg, Germany)) and powder X-ray diffraction (XRD 6000, Shimadzu Europa GmbH, Duisburg, Germany) before and after $\mathrm{Cu}$ (II) adsorption.

\subsection{Adsorption Experiments}

The study of the $\mathrm{Cu}(\mathrm{II})$ adsorption by pncom and pncm was performed by investigating the effect of $\mathrm{pH}(2-10)$, the initial copper concentration $\left(10^{-5}-9 \cdot 10^{-3} \mathrm{~mol} \cdot \mathrm{L}^{-1}\right)$ and the adsorption kinetics $(0-60$ $\mathrm{min})$. The batch-type experiments were carried out in $50 \mathrm{~mL}$ polyethylene beakers under ambient conditions as described elsewhere [8]. Specifically, the initial volume of the aqueous suspensions of magnetic biochars was $30 \mathrm{~mL}$ and the adsorbent mass $0.01 \mathrm{~g}$. The effect of the studied parameters was investigated at constant total copper concentration $5 \cdot 10^{-4} \mathrm{M}$ (except of the experiments related to the initial copper concentration) at $\mathrm{pH} 3$ and $\mathrm{pH} 6$ (except of the $\mathrm{pH}$ experiments). The $\mathrm{pH}$ was controlled by addition of $\mathrm{NaOH}$ and/or $\mathrm{HClO}_{4}(0.01$ to $1 \mathrm{M}$, Merck, Darmstadt, Germany). To reach equilibrium, the samples were placed in a thermostatic orbital shaker (100 r/min, Gallenkamp) for three days. The $\mathrm{Cu}(\mathrm{II})$ ion concentration was determined potentiometrically using a $\mathrm{Cu}(\mathrm{II})$ ion selective electrode as described elsewhere [4,5,9]. Graphing and data analysis were carried out using Kaleidagraph (4.5.2, Synergy Software, Reading, PA, USA, 2014).

The amount of copper adsorbed at time $t, q_{t}(\mathrm{mg} / \mathrm{g})$, was evaluated using the Equation (1):

$$
q_{t}=\frac{\left(C_{i}-C_{t}\right) V}{m}
$$

where $C_{i}(\mathrm{mg} / \mathrm{L})$ is the initial $\mathrm{Cu}(\mathrm{II})$ concentration in solution, $C_{t}(\mathrm{mg} / \mathrm{L})$ is the final $\mathrm{Cu}(\mathrm{II})$ concentration in solution at time $t, V(\mathrm{~L})$ is the solution volume, and $m(\mathrm{~g})$ is the dry weight of the modified biochar.

\section{Results and Discussion}

\subsection{Effect of $p H$}

The $\mathrm{pH}$ is a crucial factor regarding $\mathrm{Cu}$ (II) speciation in solution and the deprotonation of the acidic surface moieties (e.g., carboxylic-, phenolic-, hydroxy- groups) and determines the surface charge of the biochar materials. Generally, at relatively low $\mathrm{Cu}$ (II) concentrations $((\mathrm{Cu}(\mathrm{II}))<1 \mathrm{mmol})$ and up to $\mathrm{pH} 6, \mathrm{Cu}(\mathrm{II})$ is present in solution mainly as $\mathrm{Cu}^{2+}$ cations and hydrolysis becomes predominant in near neutral and alkaline solutions. The surface charge of pncm is basically related to the point of zero charge (pzc) of the magnetite present on the biochar's surface, and because the pzc of magnetite is 3.8 [17] for $\mathrm{pH}>3.8$ the negative charged moieties are expected to dominate on the pncm surface. On the other hand, the surface charge of the oxidized biochar composite (pncom) depends on both, the deprotonation of the hydroxyl groups, which are present on the magnetite surface, and the carboxylic moieties present on the surface of oxidized composite $[8,16]$.

According to Figure 1 there are significant differences regarding the adsorption behavior of pncm and pncom, basically in the acidic $\mathrm{pH}$ range $(\mathrm{pH}<6)$. In contrast to $\mathrm{Cu}(\mathrm{II})$ adsorption on pncom, which increases linearly with $\mathrm{pH}$ and reaches maximum relative adsorption values $(\sim 100 \%)$ at $\mathrm{pH} 5$, the $\mathrm{Cu}$ (II) adsorption reaches a plateau $(\sim 35 \%)$ at $\mathrm{pH}$ values between 4 and 5 and then increases steeply and reaches the maximum relative adsorption values $(\sim 100 \%)$ for $\mathrm{pH}>6$. The difference in the adsorption behavior between pncm and pncom in the acidic $\mathrm{pH}$ range is ascribed to the presence of the carboxylic groups on the pncom surface, which present increased chemical affinity for $\mathrm{Cu}$ (II) ions even in the acidic $\mathrm{pH}$ range [4,5]. On the other hand, the sharp increase of the relative adsorption observed for pncm at near neutral $\mathrm{pH}$ values could be attributed to solid phase formation and surface precipitation 
of copper salts (e.g., $\left.\mathrm{Cu}(\mathrm{OH})_{2}\right)$, which is corroborated by XRD measurements, as discussed in more detail below.

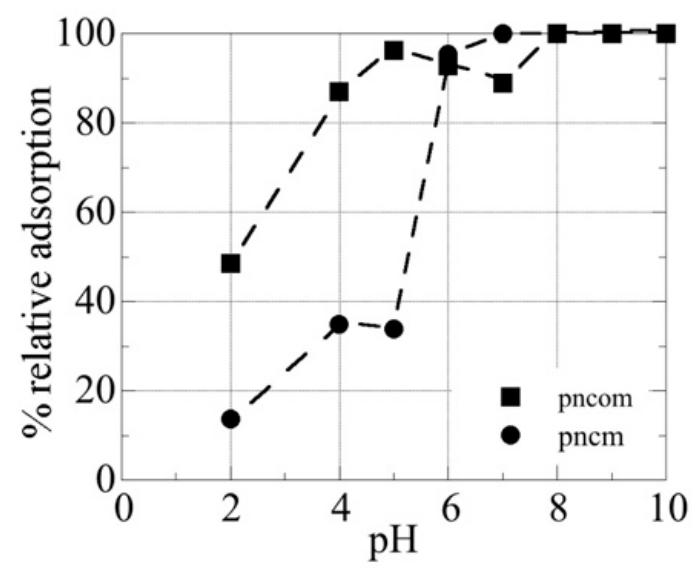

Figure 1. The $\mathrm{pH}$ effect on the adsorption efficiency of the magnetic biochar composites pncm (carbonized-magnetized pine needles) and pncom (carbonized-oxidized-magnetized pine needles) for $\mathrm{Cu}(\mathrm{II})$. The experiments were performed under ambient conditions and $(\mathrm{Cu}(\mathrm{II}))_{\text {tot }}=5 \cdot 10^{-4} \mathrm{M}$.

\subsection{XRD Measurements}

Figure 2 shows the diffractograms of adsorbent aliquots corresponding to $\mathrm{Cu}$ (II) adsorption by magnetic pine needle biochar composites pncm and pncom at $\mathrm{pH} 3$ and $\mathrm{pH} 6$ and different $\mathrm{Cu}(\mathrm{II})$ concentrations. According to the diffractograms of samples corresponding to experiments performed at $\mathrm{pH} 3$ there is no formation of copper solid phases, because under such acidic conditions the $\mathrm{Cu}$ (II) concentrations in solution are below the $\mathrm{Cu}$ (II) concentration determined by the formed solid phase. Nevertheless, the diffractograms include a peak at $2 \theta=36^{\circ}$, which corresponds to magnetite [18]. Interestingly, the magnetite peaks corresponding to the pncm samples are very small compared to the peaks in the diffractograms of pncom, indicating that on the oxidized biochar surface the magnetite formation was more effective and has resulted in the formation of larger particles.

On the other hand, the XRD diffractograms of the samples corresponding to experiments performed at $\mathrm{pH} 6$ include after a certain $\mathrm{Cu}$ (II) concentration sharp peaks, which correspond to $\mathrm{Cu}$ (II) solid phases [19]. Notably, the $\mathrm{Cu}$ (II) concentration above which the solid formation is observed is for pncm $1 \times 10^{-4} \mathrm{M}$ and for pncom $1 \times 10^{-3} \mathrm{M}$ total $\mathrm{Cu}$ (II) concentration, clearly indicating the higher $\mathrm{Cu}$ (II) adsorption capacity of pncom compared to the adsorption capacity of pncm for the same metal ions. It should be clear that when solid phase formation and surface precipitation occurs the corresponding data are useless regarding the evaluation of the maximum monolayer capacity of the adsorbents.

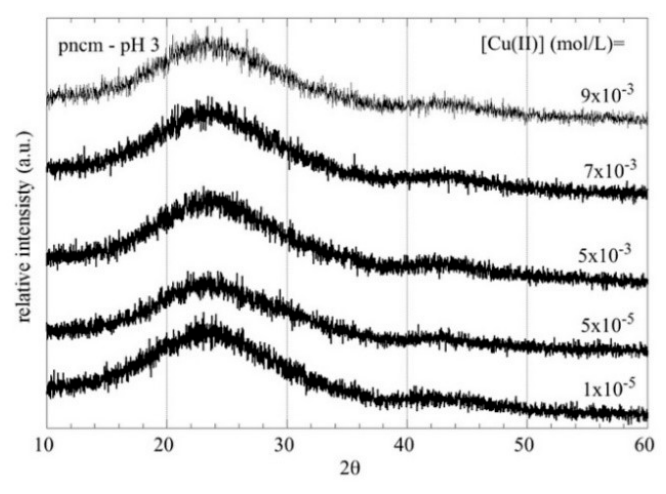

(a) X-ray diffraction (XRD) diffractograms of pncm

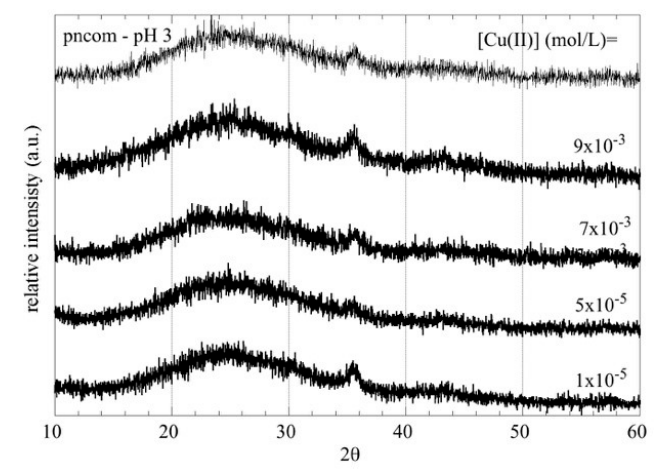

(b) pncom corresponding to $\mathrm{Cu}(\mathrm{II})$ at $\mathrm{pH} 3$

Figure 2. Cont. 


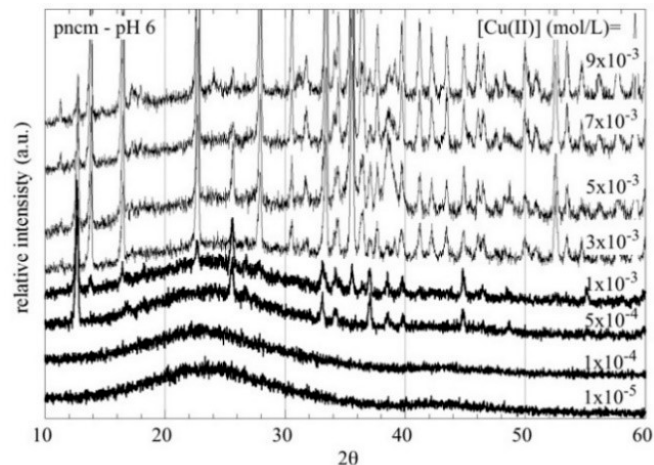

(c) X-ray diffraction (XRD) diffractograms of pncm

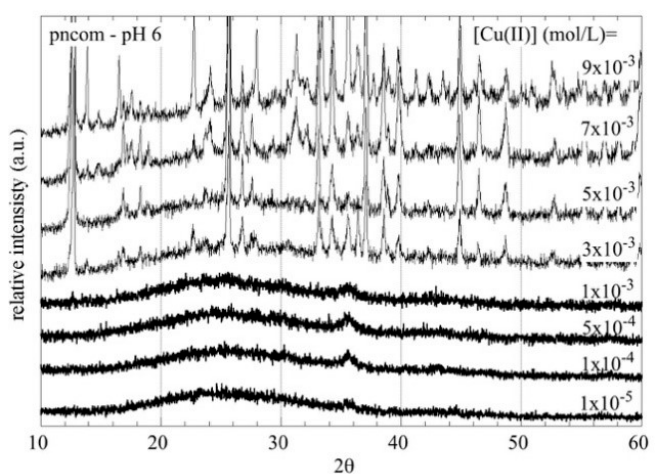

(d) pncom corresponding to $\mathrm{Cu}(\mathrm{II})$ at $\mathrm{pH} 6$

Figure 2. X-ray diffraction (XRD) diffractograms of adsorbent aliquots corresponding to $\mathrm{Cu}$ (II) adsorption by the magnetic biochar composites pncm and pncom at two different $\mathrm{pH}$ values and different $\mathrm{Cu}(\mathrm{II})$ concentration.

\subsection{Adsorption Data}

In order to determine the maximum monolayer adsorption capacity, the experimental data were fitted with the Langmuir [20] adsorption model (Equation (2)).

$$
q_{e}=q_{m} \frac{K_{L} C_{e}}{1+K_{L} C_{e}}
$$

where $C_{e}$ is the concentration (mg/L) of $\mathrm{Cu}$ (II) in solution at equilibrium, $q_{e}$ is the amount of the $\mathrm{Cu}$ (II) adsorbed per mass adsorbent $(\mathrm{mg} / \mathrm{g})$ at equilibrium, $q_{m}$ is the maximum monolayer adsorption capacity $(\mathrm{mg} / \mathrm{g})$ and $K_{L}$ is an equilibrium constant associated with the energy of adsorption. The model has been applied only to data obtained from experiments at $\mathrm{pH} 3$ (Figure 3), because at $\mathrm{pH} 6$ surface precipitation of $\mathrm{Cu}$ (II) solids occurs and only at very low $\mathrm{Cu}$ (II) concentration the $\mathrm{Cu}$ (II) adsorption by the magnetic biochars is the dominating surface-related process. The value maximum adsorption capacity evaluated applying the Langmuir adsorption model has been found to be $q_{\max }=0.40 \mathrm{mmol} \cdot \mathrm{g}^{-1}\left(25.4 \mathrm{mg} \cdot \mathrm{g}^{-1}\right)$ and $q_{\max }=1.0 \mathrm{mmol} \cdot \mathrm{g}^{-1}\left(63.5 \mathrm{mg} \cdot \mathrm{g}^{-1}\right)$ for the $\mathrm{Cu}(\mathrm{II})$ adsorption by pncm and pncom, respectively. This values are in the range of values determined for $\mathrm{Cu}(\mathrm{II})$ adsorption by magnetized and chemically modified biochars $[15,21-24]$.

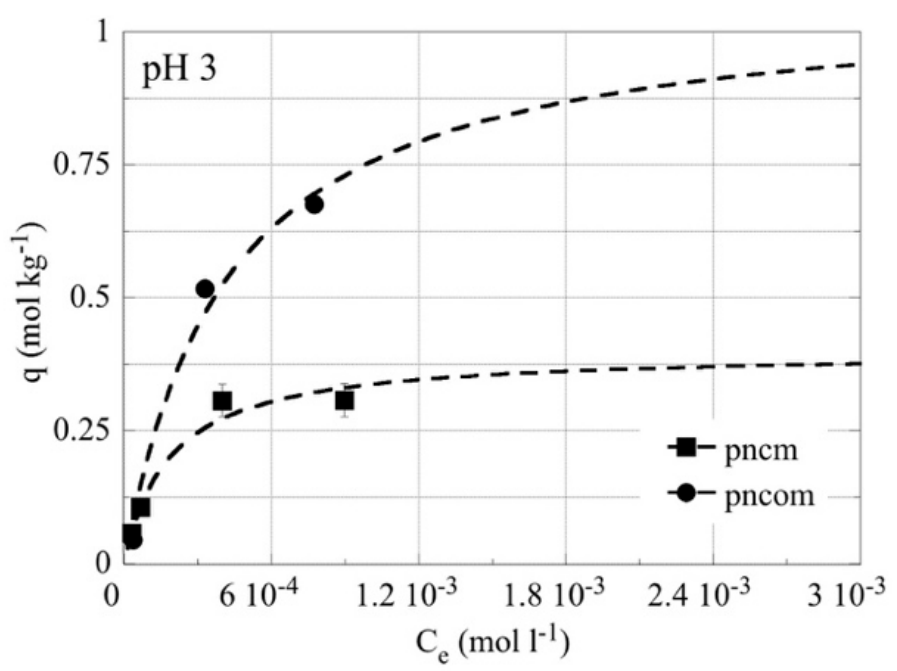

Figure 3. Experimental adsorption data and fitted curves evaluated using the Langmuir isotherm model for the $\mathrm{Cu}(\mathrm{II})$ adsorption by the magnetic biochar composites pncm and pncom. The adsorption experiments were performed under ambient conditions and $\mathrm{pH} 3$. 


\subsection{FTIR Measurements}

Figure 4 shows FTIR spectra of solid samples corresponding to experiments performed at $\mathrm{pH} 3$ and $\mathrm{pH}$ 6, and different $\mathrm{Cu}$ (II) concentrations. The FTIR spectra and particularly those corresponding to pncom show significant changes in the carbonyl range indicating also the participation of the carboxylic groups, which are present on the biochar composite surface and bind $\mathrm{Cu}(\mathrm{II})[4,5]$.

On the other hand, the additional peaks around $3500 \mathrm{~cm}^{-1}$ and between $1100 \mathrm{~cm}^{-1}$ and $500 \mathrm{~cm}^{-1}$ observed in the FTIR spectra of the solid samples corresponding to experiments performed at $\mathrm{pH}$ 6 are attributed to the formation of the $\mathrm{Cu}$ (II) solid phase (e.g., $\left.\mathrm{Cu}(\mathrm{OH})_{2}\right)$ [19]. These results are in agreement with the results obtained from XRD measurements of the corresponding samples and prove the solid phase formation and surface precipitation of $\mathrm{Cu}(\mathrm{OH})_{2}$ at increased $\mathrm{pH}$ values, which favor the $\mathrm{Cu}(\mathrm{II})$ hydrolysis [25].

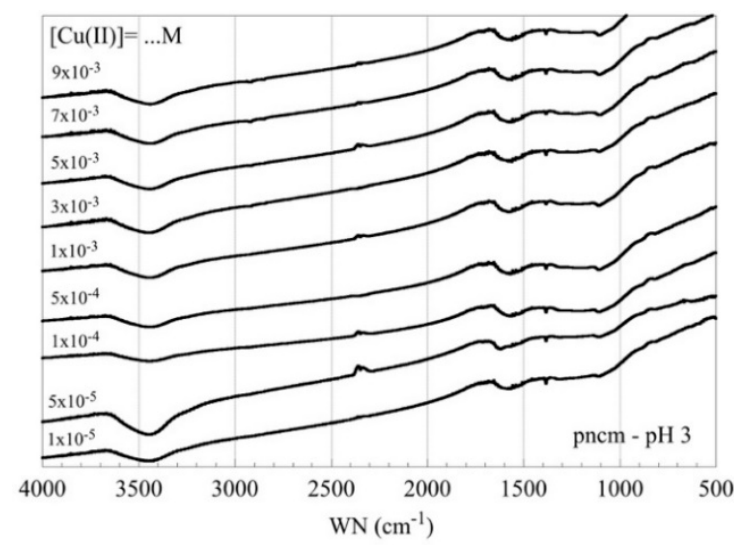

(a) Fourier transform infrared (FTIR) spectra of pncm

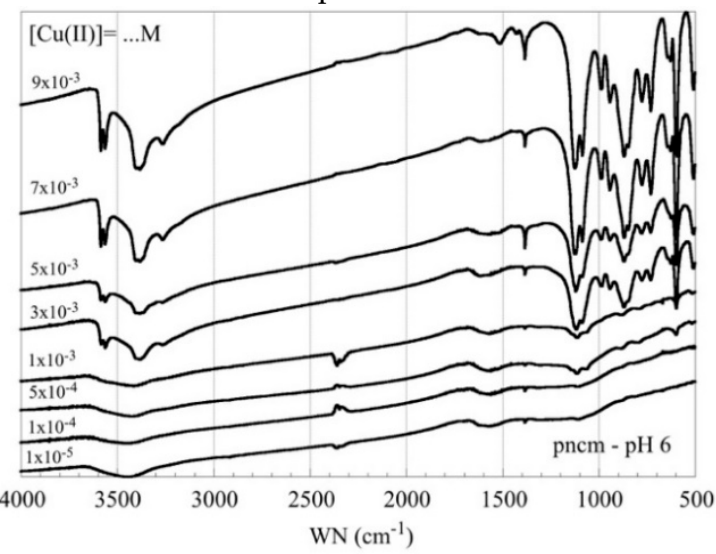

(c) Fourier transform infrared (FTIR) spectra of pncm

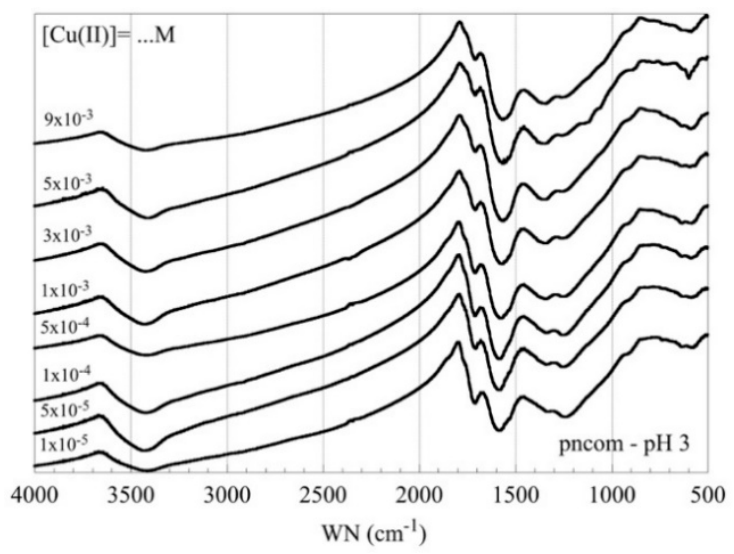

(b) pncom corresponding to $\mathrm{Cu}(\mathrm{II})$ at $\mathrm{pH} 3$

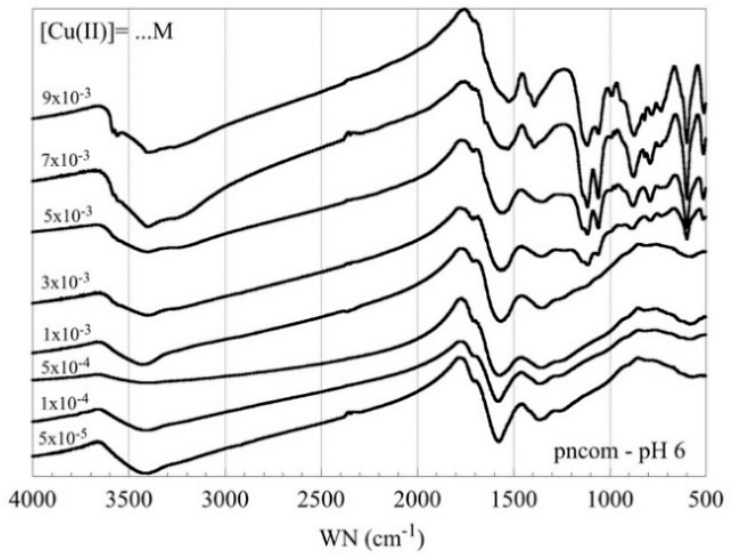

(d) pncom (right) corresponding to $\mathrm{Cu}(\mathrm{II})$ at $\mathrm{pH} 6$

Figure 4. Fourier transform infrared (FTIR) spectra of adsorbent aliquots corresponding to $\mathrm{Cu}$ (II) adsorption by the magnetic biochar composites pncm and pncom at two different $\mathrm{pH}$ values and different $\mathrm{Cu}$ (II) concentrations. The spectra have been obtained in the wavenumber (WN) range between 4000 and $500 \mathrm{~cm}^{-1}$.

Generally, $\mathrm{Cu}(\mathrm{II})$ binding by magnetized biochars can occur through pi-cation interactions and complex formation between the carboxylic moieties [26], which are present on the surface of oxidized biochar composite and the metal cations, as well as surface complexation of $\mathrm{Cu}(\mathrm{II})$ cations by the hydroxo groups [26] present on the magnetite particle surface (Figure 5). 


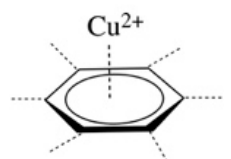

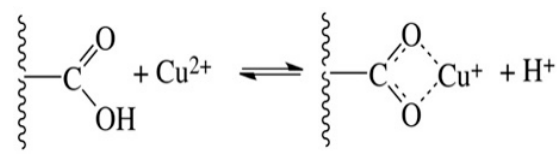<smiles>CC(O)CC(C)O</smiles>

Figure 5. Schematic illustration of the different binding modes of $\mathrm{Cu}(\mathrm{II})$ cations by magnetized biochars.

\subsection{Kinetic Studies}

The effect of contact time was examined in a range between 0 and $60 \mathrm{~min}$ at two different $\mathrm{pH}$ values. The adsorption was found to be relatively fast and $\mathrm{Cu}$ (II) was adsorbed almost quantitatively in the first $10 \mathrm{~min}$. The estimation of copper uptake is an essential parameter for the development of an effective and accurate design for large scale adsorption processes.

For this purpose the experimental kinetic data were fitted with the pseudo-first-order (Equation (3)) [27] and pseudo-second-order kinetic (Equation (4)) models [28,29], in their linearized form:

$$
\begin{gathered}
\ln \left(q_{e}-q_{t}\right)=\ln \left(q_{e}\right)-k_{1} t \\
\frac{t}{q_{t}}=\frac{1}{k_{2} q_{e}^{2}}+\frac{1}{q_{e}} t
\end{gathered}
$$

where $q_{e}\left(\mathrm{mg} \mathrm{g}^{-1}\right)$ and $q_{t}$ are the amounts of adsorbed $\mathrm{Cu}(\mathrm{II})$ on the biochar at the equilibrium and at any time $t$, respectively. For the pseudo-first-order kinetic model the $q_{e}$ and $k_{1}$ can be calculated from the slope and intercept obtained from the plots $\ln \left(q_{\mathrm{e}}-q_{t}\right)$ versus $t$. For the pseudo-second-order kinetic model the $q_{e}$ and $k_{2}$ can be calculated from the slopes and the intercept of the plot $\frac{t}{q_{t}}$ versus $t$.

The constants of the kinetic models are summarized in Table 1. According to Table 1, the experimental data are well fitted with the pseudo-second order kinetics and the associated curves are shown in Figure 6. The pseudo-second order kinetics is characteristic for magnetic biochar adsorbents and the evaluated $k_{2}$ values are similar to corresponding literature $k_{2}$ values $[15,21-24,30]$.

Table 1. Kinetic parameters evaluated for the $\mathrm{Cu}(\mathrm{II})$ adsorption by pncm and pncom at $\mathrm{pH} 3$ and $\mathrm{pH}$ 6, and evaluated by fitting the experimental data with the pseudo-first and pseudo-second order

\begin{tabular}{|c|c|c|c|c|c|c|c|c|}
\hline \multirow[b]{3}{*}{$\mathrm{pH}$} & \multicolumn{4}{|c|}{ Pseudo-First-Order } & \multicolumn{4}{|c|}{ Pseudo-Second-Order } \\
\hline & \multicolumn{2}{|c|}{ pncm } & \multicolumn{2}{|c|}{ pncom } & \multicolumn{2}{|l|}{ pncm } & \multicolumn{2}{|c|}{ pncom } \\
\hline & $\begin{array}{c}\mathrm{k}_{1} \\
\left(\min ^{-1}\right)\end{array}$ & $\mathbf{R}$ & $\begin{array}{c}\mathrm{k}_{1} \\
\left(\min ^{-1}\right)\end{array}$ & $\mathbf{R}$ & $\begin{array}{c}\mathrm{k}_{2} \\
\left(\mathrm{~g} \cdot \mathrm{mg}^{-1} \cdot \mathrm{min}^{-1}\right)\end{array}$ & $\mathbf{R}$ & $\frac{\mathrm{k}_{2}}{\left(\mathrm{~g} \cdot \mathrm{mg}^{-1} \cdot \mathrm{min}^{-1}\right)}$ & $\mathbf{R}$ \\
\hline 3 & 0.199 & 0.583 & 0.002 & 0.187 & 1.525 & 0.998 & 3.525 & 0.996 \\
\hline 6 & 0.001 & 0.126 & 0.001 & 0.992 & 0.939 & 0.999 & 0.746 & 0.999 \\
\hline
\end{tabular}
kinetic models.
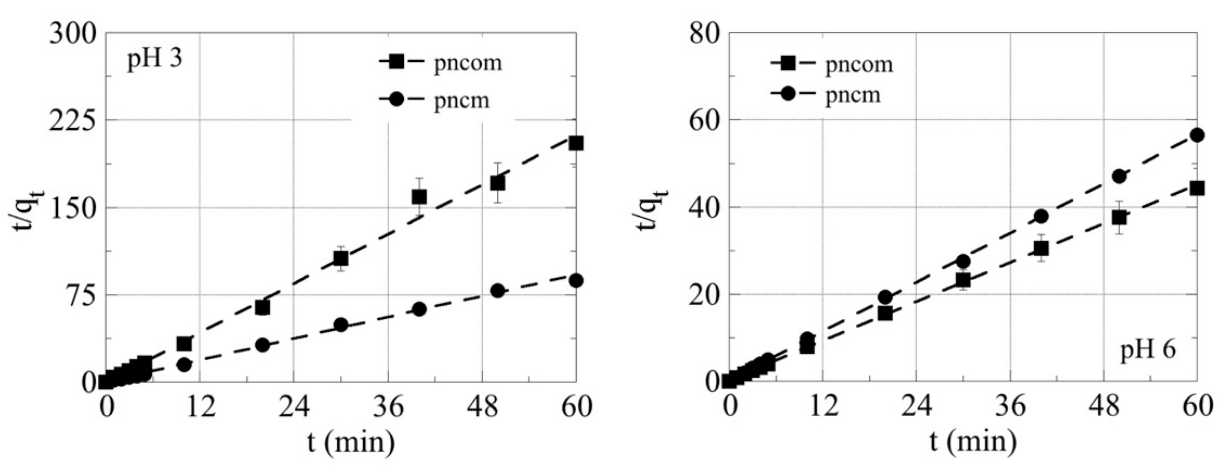

Figure 6. Kinetic experimental data and fitted curves using the pseudo second kinetic model for the $\mathrm{Cu}$ (II) adsorption by the magnetic biochar composites pncm and pncom. The adsorption experiments were performed under ambient conditions and two different $\mathrm{pH}$ values. 


\section{Conclusions}

The conclusions that can be drawn from the present study are: (a) Biochar magnetization after oxidation results in significantly higher adsorption capacities due to the synergistic effect of the carboxylic moieties, which favor iron oxide deposition on the biochar surface and complex $\mathrm{Cu}(\mathrm{II})$ ions even at low $\mathrm{pH}(\mathrm{pH}<4)$; (b) The adsorption process follows the pseudo-second order kinetics; and (c) FTIR measurements denote the formation of inner-sphere complexes and XRD data show $\mathrm{Cu}$ (II) surface precipitation at $\mathrm{pH} 6$ and increased $\mathrm{Cu}$ (II) concentration. Generally, magnetisation of biochar results in better adsorption capacity and desired properties regarding magnetic-based separation.

Author Contributions: Conceptualization, I.P.; Data curation, E.N., K.P. and I.P.; Formal analysis, E.N., K.P. and I.P.; Investigation, E.N. and K.P.; Project administration, K.P. and I.P.; Supervision, I.P.; Validation, K.P. and I.P.; Visualization, E.N.; Writing—original draft, I.P.; Writing—review \& editing, K.P. and I.A.

Funding: This research received no external funding.

Conflicts of Interest: The authors declare no conflict of interest.

\section{References}

1. Kurniawan, T.A.; Chan, G.Y.S.; Lo, W.H.; Babel, S. Physico-chemical treatment techniques for wastewater laden with heavy metals. Chem. Eng. J. 2006, 118, 83-98. [CrossRef]

2. Michalak, I.; Chojnacka, K.; Witek-Krowiak, A. State of the art for the biosorption process-A review. Appl. Biochem. Biotechnol. 2013, 170, 1389-1416. [CrossRef] [PubMed]

3. Liu, W.J.; Jiang, H.; Yu, H.Q. Development of biochar-based functional materials: Toward a sustainable platform carbon material. Chem. Rev. 2015, 115, 12251-12285. [CrossRef] [PubMed]

4. Hadjittofi, L.; Prodromou, M.; Pashalidis, I. Activated biochar derived from cactus fibres-preparation, characterization and application on $\mathrm{Cu}$ (II) removal from aqueous solutions. Bioresour. Technol. 2014, 159, 460-464. [CrossRef]

5. Liatsou, I.; Constantinou, P.; Pashalidis, I. Copper binding by activated biochar fibres derived from Luffa Cylindrica. Water AirSoil Pollut. 2017, 228, 255. [CrossRef]

6. Zhou, Q.; Liao, B.; Lin, L.; Qiu, W.; Song, Z. Adsorption of Cu (II) and Cd (II) from aqueous solutions by ferromanganese binary oxide-biochar composites. Sci. Total Environ. 2018, 615, 115-122. [CrossRef]

7. Hadjiyiannis, P.; Pashalidis, I. Copper (II) adsorption by Opuntia ficus-indica biochar fiber-MnO $\mathrm{M}_{2}$ composites. Desalin. Water Treat. 2019, 159, 60-65. [CrossRef]

8. Philippou, K.; Savva, I.; Pashalidis, I. Uranium(VI) binding by pine needles prior and after chemical modification. J. Radioanal. Nucl. Chem. 2018, 318, 2205-2211. [CrossRef]

9. Liatsou, I.; Pashalidis, I.; Dosche, C. Cu(II) adsorption on 2-thiouracil-modified Luffa Cylindrica biochar fibres from artificial and real samples, and competition reactions with U(VI). J. Hazard. Mater. 2019. [CrossRef]

10. Thompson, K.A.; Shimabuku, K.K.; Kearns, J.P.; Knappe, D.R.; Summers, R.S.; Cook, S.M. Environmental comparison of biochar and activated carbon for tertiary wastewater treatment. Environ. Sci. Technol. 2016, 50, 11253-11262. [CrossRef]

11. Nair, V.D.; Nair, P.K.R.; Dari, B.; Freitas, A.M.; Chatterjee, N.; Pinheiro, F.M. Biochar in the Agroecosystem-Climate-Change-Sustainability Nexus. Front. Plant Sci. 2017, 8, 2051. [CrossRef] [PubMed]

12. Rangabhashiyam, S.; Balasubramanian, P. The potential of lignocellulosic biomass precursors for biochar production: Performance, mechanism and wastewater application-A review. Ind. Crops Prod. 2019, 128, 405-423. [CrossRef]

13. Hadjittofi, L.; Pashalidis, I. Uranium sorption from aqueous solutions by activated biochar fibres investigated by FTIR spectroscopy and batch experiments. J. Radioanal. Nuclear Chem. 2015, 304, 897-904. [CrossRef]

14. Liatsou, I.; Pashalidis, I.; Oezaslan, M.; Dosche, C. Surface characterization of oxidized biochar fibers derived from Luffa Cylindrica and lanthanide binding. J. Environ. Chem. Eng. 2017, 5, 4069-4074. [CrossRef]

15. Kołodyńska, D.; Bakk, J. Use of three types of magnetic biochar in the removal of copper (II) ions from wastewaters. Sep. Sci. Technol. 2018, 53, 1045-1057. [CrossRef]

16. Oliveira, L.C.A.; Rios, R.V.R.A.; Fabris, J.D.; Garg, V.; Sapag, K.; Lago, R.M. Activated carbon/iron oxide magnetic composites for the adsorption of contaminants in water. Carbon 2002, 40, 2177-2183. [CrossRef] 
17. Milonjić, S.; Kopečni, M.; Ilić, Z. The point of zero charge and adsorption properties of natural magnetite. J. Radioanal. Chem. 1983, 78, 15-24. [CrossRef]

18. Majumder, S.; Sardar, M.; Satpati, B.; Kumar, S.; Banerjee, S. Magnetization Enhancement of $\mathrm{Fe}_{3} \mathrm{O}_{4}$ by Attaching onto Graphene Oxide: An Interfacial Effect. J. Phys. Chem. C 2018, 122, 21356-21365. [CrossRef]

19. Devamani, R.H.P.; Alagar, M. Synthesis and characterisation of copper II hydroxide nano particles. Nano Biomed. Eng. 2013, 5, 116-120. [CrossRef]

20. Langmuir, I. The adsorption of gases on plane surfaces of glass, mica and platinum. J. Am. Chem. Soc. 1918, 40, 1361-1403. [CrossRef]

21. Nyamunda, B.C.; Chivhanga, T.; Guyo, U.; Chigondo, F. Removal of Zn (II) and Cu (II) Ions from Industrial Wastewaters Using Magnetic Biochar Derived from Water Hyacinth. J. Eng. 2019. [CrossRef]

22. Son, E.B.; Poo, K.M.; Chang, J.S.; Chae, K.J. Heavy metal removal from aqueous solutions using engineered magnetic biochars derived from waste marine macro-algal biomass. Sci. Total Environ. 2018, 615, 161-168. [CrossRef] [PubMed]

23. Song, Q.; Yang, B.; Wang, H.; Xu, S.; Cao, Y. Effective removal of copper (II) and cadmium (II) by adsorbent prepared from chitosan-modified magnetic biochar. J. Residuals Sci. Technol 2016, 13, 197-205. [CrossRef]

24. Yin, Z.; Liu, Y.; Liu, S.; Jiang, L.; Tan, X.; Zeng, G.; Li, M.; Liu, S.; Tian, S.; Fang, Y. Activated magnetic biochar by one-step synthesis: Enhanced adsorption and coadsorption for $17 \beta$-estradiol and copper. Sci. Total Environ. 2018, 639, 1530-1542. [CrossRef] [PubMed]

25. Baes, C.F.; Mesmer, R.E. The Hydrolysis of Cations; John Wiley \& Sons: New York, NY, USA, 1976; Volume 81, pp. 245-246.

26. Philippou, K.; Anastopoulos, I.; Dosche, C.; Pashalidis, I. Synthesis and characterization of a novel $\mathrm{Fe}_{3} \mathrm{O}_{4}$-loaded oxidized biochar from pine needles and its application for uranium removal. Kinetic, thermodynamic, and mechanistic analysis. J. Environ. Manag. 2019, 252, 109677. [CrossRef] [PubMed]

27. Lagergren, S. About the theory of so-called adsorption of soluble substances. Sven. Vetensk. Handingarl 1898, 24, 1-39.

28. Blanchard, G.; Maunaye, M.; Martin, G. Removal of heavy metals from waters by means of natural zeolites. Water Res. 1984, 18, 1501-1507. [CrossRef]

29. Ho, Y.S.; McKay, G. Pseudo-second order model for sorption processes. Process Biochem. 1999, 34, 451-465. [CrossRef]

30. Xiao, F.; Cheng, J.; Cao, W.; Yang, C.; Chen, J.; Luo, Z. Removal of heavy metals from aqueous solution using chitosan-combined magnetic biochars. J. Colloid Interface Sci. 2019, 540, 579-584. [CrossRef] 